\title{
Management of Acute Periapical Lesions at Four Mandibular Incisors a Case Report
}

\author{
Nedim Smajkic* \\ Specialist Endodontic, Private Dental Practice, Bosnia and Herzegovina
}

Submission: May 07, 2017; Published: June 13, 2017

*Corresponding author: Nedim Smajkic DDS, MSc PhD, Private Dental Practice, St. Antuna Branka Simica 27, 71000 Sarajevo; Bosnia and Herzegovina, Tel: +387-61-709-503; Email: nedim@drsmajkic.ba

\begin{abstract}
Depending on the severity of irritation, duration, and host response, periradicular pathology may range from mild inflammation to extensive tissue destruction. This case report is showing the failures of previous endodontic treatment and apical surgery that resulted with exacerbation with phoenix abscess and try to preserve the four teeth with joined periapical lesions with endodontic retreatment and medicament therapy only.

Fourteen year old female patient addressed to the dental office with swelling and pain in the mental area of the mandible. All mandibular incisors were painful with swelling of soft tissue. After the emergency treatment, and endodontic therapy of all involved teeth during the period of 10 months on $\mathrm{x}$-ray radiogram was noticed a large reduction of radiolucency in the apical region. In this case, the used medicament in combination with NiTi rotary instruments for root canal preparation and Gutta Flow with a gutta-percha point as obturation reduced the cause of the acute periapical inflammation. This was confirmed by satisfactory reparation of the periapical tissue after the control period of two and ten months. After only endodontic retreatment, of all involved teeth the bone inflammation is cured with a prognosis of good repair of bone defects.
\end{abstract}

Keywords: Periapical lesions; Endodontic therapy; Gutta flow obturation; Dental abscess

\section{Introduction}

This case report is showing the failure of previous endodontic treatment and apical surgery that resulted with exacerbation with phoenix abscess and effort to preserve the four teeth with joined periapical lesions with endodontic retreatment and medicament therapy only. There is causality between changes in the periapical tissue and the changes arising in the dental pulp due to infection and other etiological causes. In contrast to a pulp, periradicular tissues have an almost unlimited source of undifferentiated cells that participate in inflammation as well as repair. In addition, these tissues have rich collateral blood supply and lymph drainage. These characteristics counteract the destructive elements related to irritants from the canal space and result inflammation [1]. Depending on the severity of irritation, duration, and host response, periradicular pathology may range from mild inflammation to extensive tissue destruction. The injury usually results in cellular damage and release of nonspecific as well as specific immunologic mediators of inflammatory response [2].

In current clinical practice, the treatment of infected periapical tissue is successfully achieved by mechanical debridement, medicament therapy, and correct obturation of the root canal and prognosis of the therapy are very good with a high percentage of cured teeth. Calcium hydroxide usually is in use as an intracanal medication in the treatment of necrotic teeth because of its favorable alkalizing effect [3]. Calcium hydroxide is used to slow or reverse external root resorption subsequent to trauma. Analyses of calcium ion concentrations of extra radicular samples revealed that dentin specimens varied in their rates of diffusion of calcium and that treatment of the canals with various agents affected the amounts of calcium recovered [4]. Comparative studies show that calcium hydroxide is superior to any other intracanal medication for the elimination of remaining bacteria. It is suggested that the action comes from diffusion of hydroxyl ions through the apical foramen [5].

Hosoya et al. [6] suggests that the time required for optimum intracanal activity when using calcium hydroxide mixtures is at least 2 weeks [6]. Ercan et al. [7] found that a combination of calcium hydroxide and 1\% chlorhexidine can be successfully used as an intra canal medicament for disinfection in endodontic retreatment with periapical lesions [7]. In the situation, when root 
canal therapy cannot be successfully done because of obstruction of the apical part of a root canal or it is a present of apical cyst the endodontic surgery is necessary for tooth preservation.

\section{Case Report}

Fourteen year old female patient addressed to the dental office with swelling and pain in the mental area of the mandible. All mandibular incisors were painful with swelling of soft tissue. On the x-ray radiogram it was noticed the large radiolucency on an apical region of teeth: $42,41,31$ and 32 . A teeth 42,41 and 31 has a weak root canal filing and tooth 32 have a root canal overfilling with post and prosthetic crown (Figure 1). In the patient history, it was found, that on three lower incisors, she had first endodontic treatment two years ago. After first endodontic treatment, she had exacerbation whit pain and swelling, and she was referred to the surgeon. The surgeon did periapical surgery on teeth 42,41 and 31 without endodontic retreatment of involved teeth. A couple months after surgery patient have again swelling with pain in the same region.

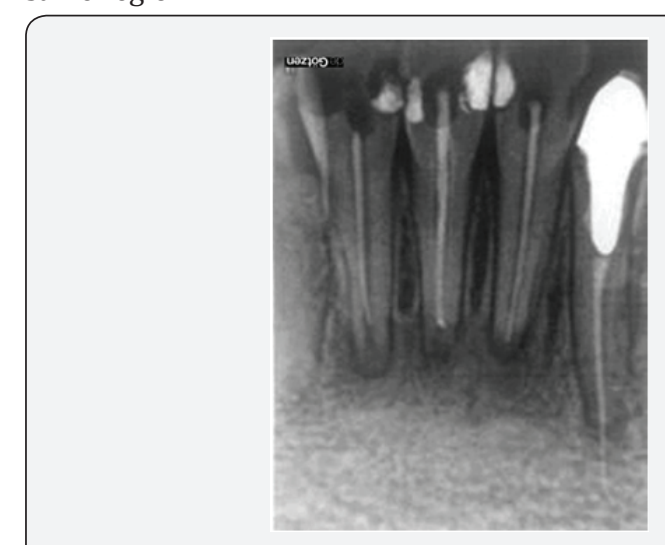

Figure 1: Patient $x$-ray before emergency treatment.

After establishing patients problem endodontic emergency treatment was done, removal of root canal filling at all involved teeth to achieve a pus drainage through root canals. The crown, post and root canal filling on tooth 34 was also removed. The patient was received a prescription for Amoxicillin whit Clavunaic acid $625 \mathrm{mg}$ at a period of five days (Xiclave, Bosnalijek, Bosnia and Herzegovina) for infection control and Ibuprofen 600mg (Ibuprofen, Belupo, Croatia) for pain control. After withdrawal the abscess and cessation of pain the root canals of all four teeth were prepared with NiTi rotary files M-two and File Care EDTE (VDW, Germany). NiTi file 30/. 05 was the last used for preparation of all root canals and sodium hypochlorite was used for irrigation and disinfection. After the debridement, calcium hydroxide paste (CALXYD, Spofa Dental, Czech Republic) was placed on a length of 7 days for the control that swelling and pain do not return.

After seven days, all four teeth where without any pain, calcium hydroxide paste was removed from root canals. Root canals were filled with silicon based flow gutta-percha system (GuttaFlow, ColtèneWhaledent, Switzerland) as a sealer and master guttapercha point M-two gutta-percha 30/.05 (VDW, Germany). The point of master gutta-percha cone was cut off on the working length determination. On this way it was obtained that 05 tapered guttapercha point tightly fit at the open end of the root canal to achieve good apical seal. Immediately after root canal filing radiogram was taken to control root canals filling quality. (Figure 2) Recalls were done for repeat $\mathrm{x}$-ray radiogram after two months (Figure 3) and 10 months (Figure 4) after treatment to control healing process in the apical region of treated teeth. All dental x-ray radiograms after treatment were done with the digital dental imaging system (deGötzen, Italy)

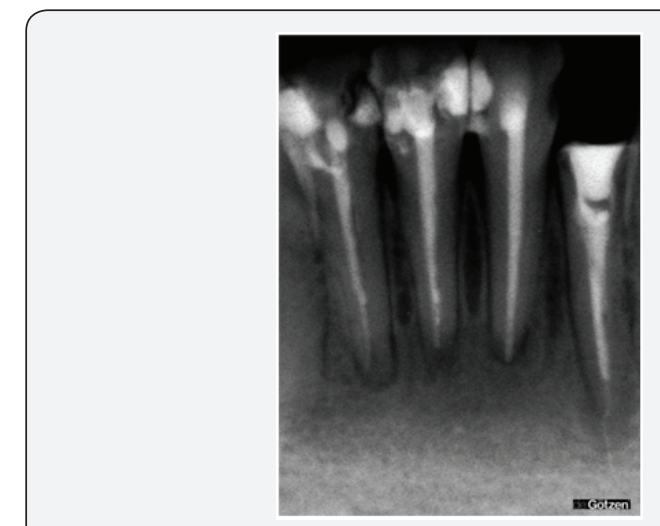

Figure 2: X-ray image after root canals obturation with Gutta Flow sealer and Gutta-percha master point.

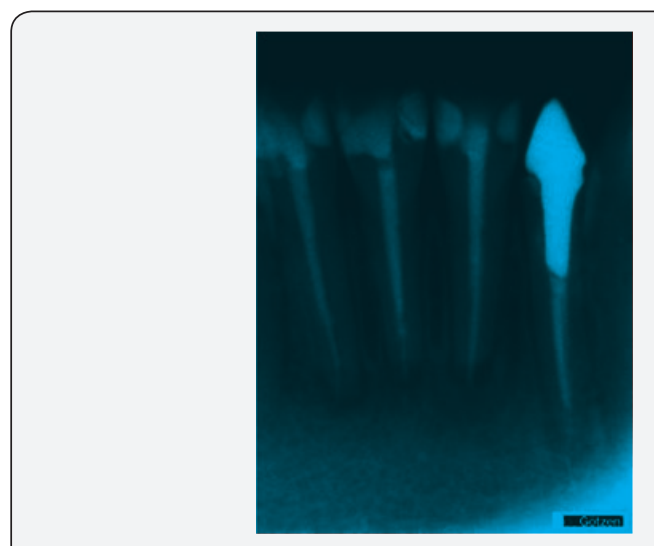

Figure 3: X-ray image two month after treatment.

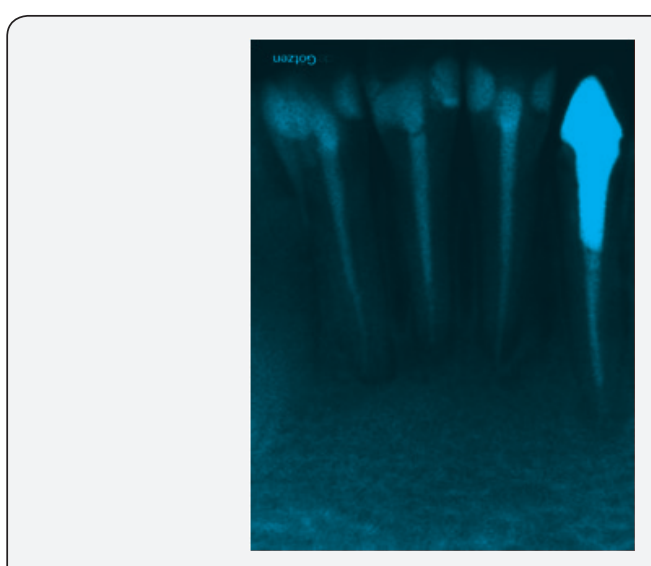

Figure 4: X-ray image ten month after treatment. 


\section{Results}

After only endodontic retreatment, of all involved teeth, adequate mechanical debridement, and intra canal medicament therapy with calcium hydroxide, and obturation of the root canals with Gutta Flow sealer and gutta-percha master point, the periapical lesions is showing satisfactory reparation according $\mathrm{x}$-ray images in control period of 4 and 10 months with a good prognosis of total repair of bone defects. Also patient did not report any subjective symptoms after the treatment and during control period.

\section{Discussion}

The lower tree incisors had failed periapical surgery whit inadequate endodontic treatment with poor root canal filling, and one incisor was overfilled with the presence of strong bone inflammation with suppuration when 14 year old patient visited dental office. After the emergency treatment, end endodontic retreatment of all involved teeth during the observation period of 10 months, it was noticed on radiogram large reduction of radiolucency in the apical region.

In this case, the used medicaments in combination with NiTi rotary instruments for root canal debridement, preparation and Gutta Flow with a gutta-percha point as obturation reduced the cause of the acute periapical process. This was confirmed by satisfactory reparation of the periapical tissue after the control period of two and ten months. Root canal preparation techniques with engine driven greater-tapered instruments significantly reduced the number of bacteria in the root canal [8]. Sodium hypochlorite irrigation for the control of root canal infection in combination with calcium hydroxide dressing showed good efficiency in disinfection of the root canal system and treatment outcome [9]. An aqueous calcium hydroxide paste shows better efficiency at raising the $\mathrm{pH}$ than the other calcium hydroxide based materials [10].

In research of Peters \& Wesselink [11] the size of the periapical lesions, at healing evaluation, reduced significantly during the follow-up period. Complete radiographic healing was observed in $81 \%$ of the cases in the one-visit group, and in $71 \%$ of the cases in the two-visit group. The probability of success increased continuously over time for both treatment groups. Seven out of eight cases $(87.5 \%)$ that showed a positive root-canal culture at the time of obturation healed [11].

Antibiotics are commonly used in dental practice. It has been estimated that $10 \%$ of all antibiotic prescriptions are related to dental infections. The association amoxicillin-clavulanate was the drug most frequently prescribed by dentists during 2005 [12]. Antibiotics are indicated for the treatment of odontogenic infections, oral non-odontogenic infections, as prophylaxis against focal infection, and as prophylaxis against local infection and spread to neighboring tissues and organs. For dental acute infection with abscess co-amoxiclav showed good effectiveness in therapy [13]. It is accepted that all inflammatory periapical lesions should be initially treated with conventional nonsurgical procedures. Studies have reported a success rate of up to $85 \%$ after endodontic treatment of teeth with periapical lesions [14].

\section{References}

1. Weine FS (1996) Endodontics Therapy. ( $5^{\text {th }}$ edn), Mosby Maryland Heights, Missouri, USA, pp. 426-433.

2. Walton RE, Torabinjad M (1996) Principles and practice of Endodontics. ( $\left.2^{\text {nd }} e d n\right)$, Saunders, Philadelphia, USA, pp. 234-239.

3. Zmener O, Pameijer CH, Banegas G (2007) An in vitro study of the pHof three calcium hydroxide dressing materials. Dent Traumatol 23(1): 2125.

4. Deardorf KA, Swartz ML, Newton CW, Brown CE (1994) Effect of root canal treatments on dentin permeability. J Endod 20(1): 1-5.

5. Naaman A, Kaloustian H, Ounsi HF, Naaman-BouAbboud N, Ricci C, et al. (2007) Scanning Electron Microscopic Evaluation of Root Canal Wall Cleanliness after Calcium Hydroxide Removal Using ThreeIrrigation Regimens. J Contemp Dent Pract 8(1): 11-18.

6. Hosoya N, Takahashi G, Arai T, Nakamura J (2001) Calcium concentration and $\mathrm{pH}$ of the periapical environment after applying calcium hydroxide into root canals in vitro. J Endod 27(5): 343-346.

7. Ercan E, Dalli M, Dulgergil CT, Yaman F (2007) Effect of intracanal medication with calcium hydroxide and $1 \%$ chlorhexidine in endodonticretreatment cases with periapical lesions: an in vivo study. J Formos Med Assoc 106(3): 217-224.

8. Aydin C, Tunca YM, Senses Z, Baysallar M, Kayaoglu G, et al. (2007) Bacterial reduction by extensive versus conservative root canal instrumentation in vitro. Acta Odontol Scand 65(3): 167-170.

9. Waltimo T, Trope M, Haapasalo M, Orstavik D (2005) Clinical efficacy of treatment procedures in endodontic infection control and one year follow-up of periapical healing. J Endod 31(12): 863-866.

10. Ardeshna SM, Qualtrough AJ, Worthington HV (2002) An in vitro comparison of $\mathrm{pH}$ changes in root dentine following canal dressing with calcium hydroxide points and a conventional calcium hydroxide paste. Int Endod J 35(3): 239-244.

11. Peters LB, Wesselink PR (2002) Periapical healing of endodontically treated teeth in one and two visits obturated in the presence or absence of detectable microorganisms. Int Endod J 35(8): 660-667.

12. Poveda Roda R, Bagan JV, SanchisBielsa JM, Carbonell Pastor E (2007) Antibiotic use in dental practice. A review. Med Oral Patol Oral Cir Bucal 12(3): E186-E192.

13. Lewis MA, Carmichael F, MacFarlane TW, Milligan SG (1993) A randomised trial of co-amoxiclav (Augmentin) versus penicillin $\mathrm{V}$ in the treatment of acute dentoalveolar abscess. Br Dent J 175(5): 169174.

14. Fernandes M, de Ataide I (2010) Nonsurgical management of periapical lesions. J Conserv Dent 13(4): 240-245. 
This work is licensed under Creative Commons Attribution 4.0 Licens

DOI: 10.19080/ADOH.2017.05.555654
Your next submission with Juniper Publishers will reach you the below assets

- Quality Editorial service

- Swift Peer Review

- Reprints availability

- E-prints Service

- Manuscript Podcast for convenient understanding

- Global attainment for your research

- Manuscript accessibility in different formats

( Pdf, E-pub, Full Text, Audio)

- Unceasing customer service

Track the below URL for one-step submission https://juniperpublishers.com/online-submission.php 